\title{
STUDIES
}

Vol. 14, no 2

April 2015

Unless otherwise indicated, the contents of

Peake STUDIES are (C) G. Peter Winnington 2015.

Artwork by Mervyn Peake (C) the Mervyn Peake Estate.

Acknowledgement is made to the Mervyn Peake Estate for permission to reproduce Mervyn Peake's words and images.

Edited and published by

G. Peter Winnington, 2 ch. du Collège,

1453 Mauborget, Switzerland.

Tel. +41244362232

E-mail peakestudies@gmail.com

Home page http://peakestudies.com 
10.1515/peakest-2015-0001

\section{Peake House}

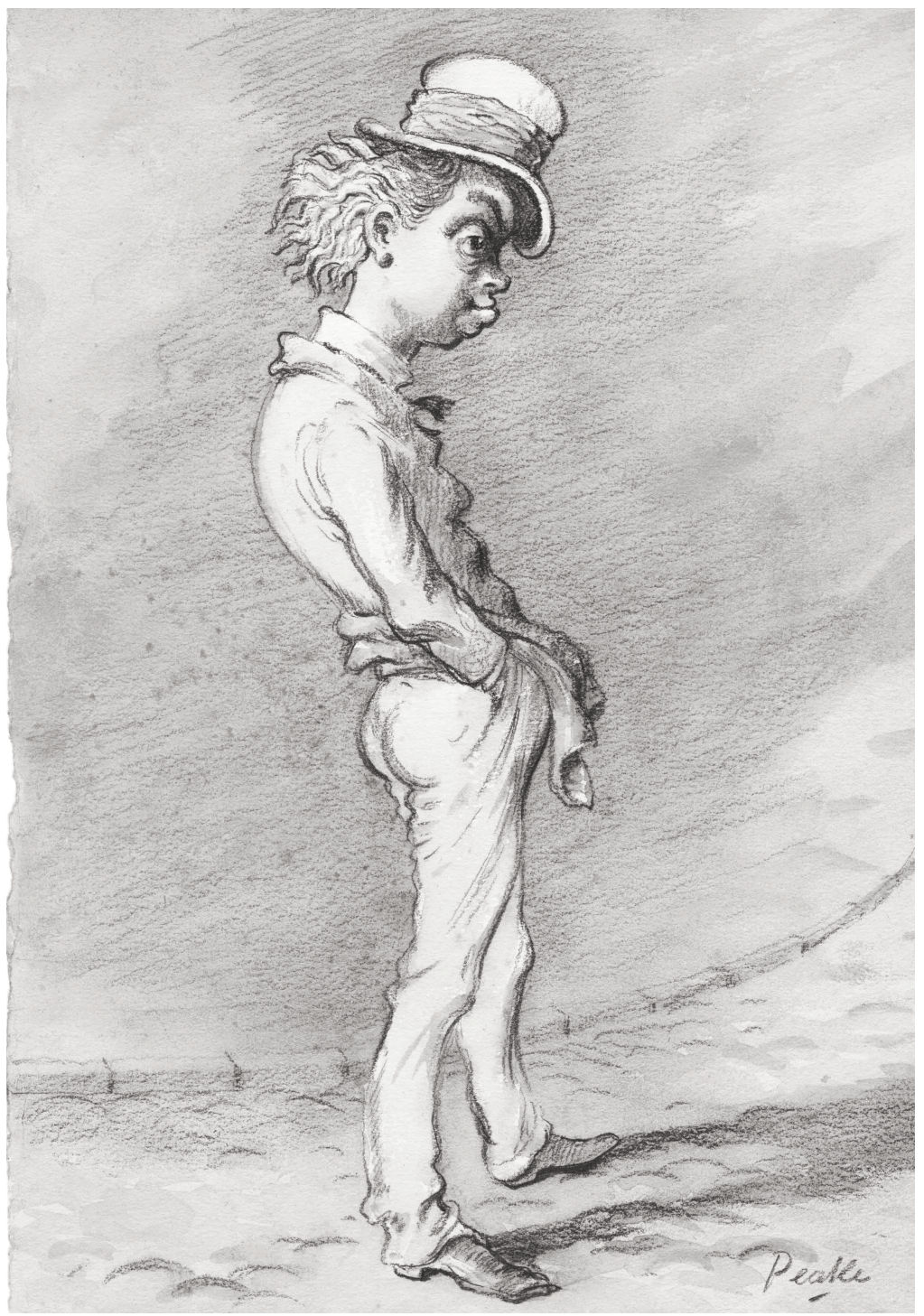


More of Peake' wonderful illustrations for Bleak House have come to light. On the previous page is Mr Guppy; below are Mrs Pardiggle's three sons,

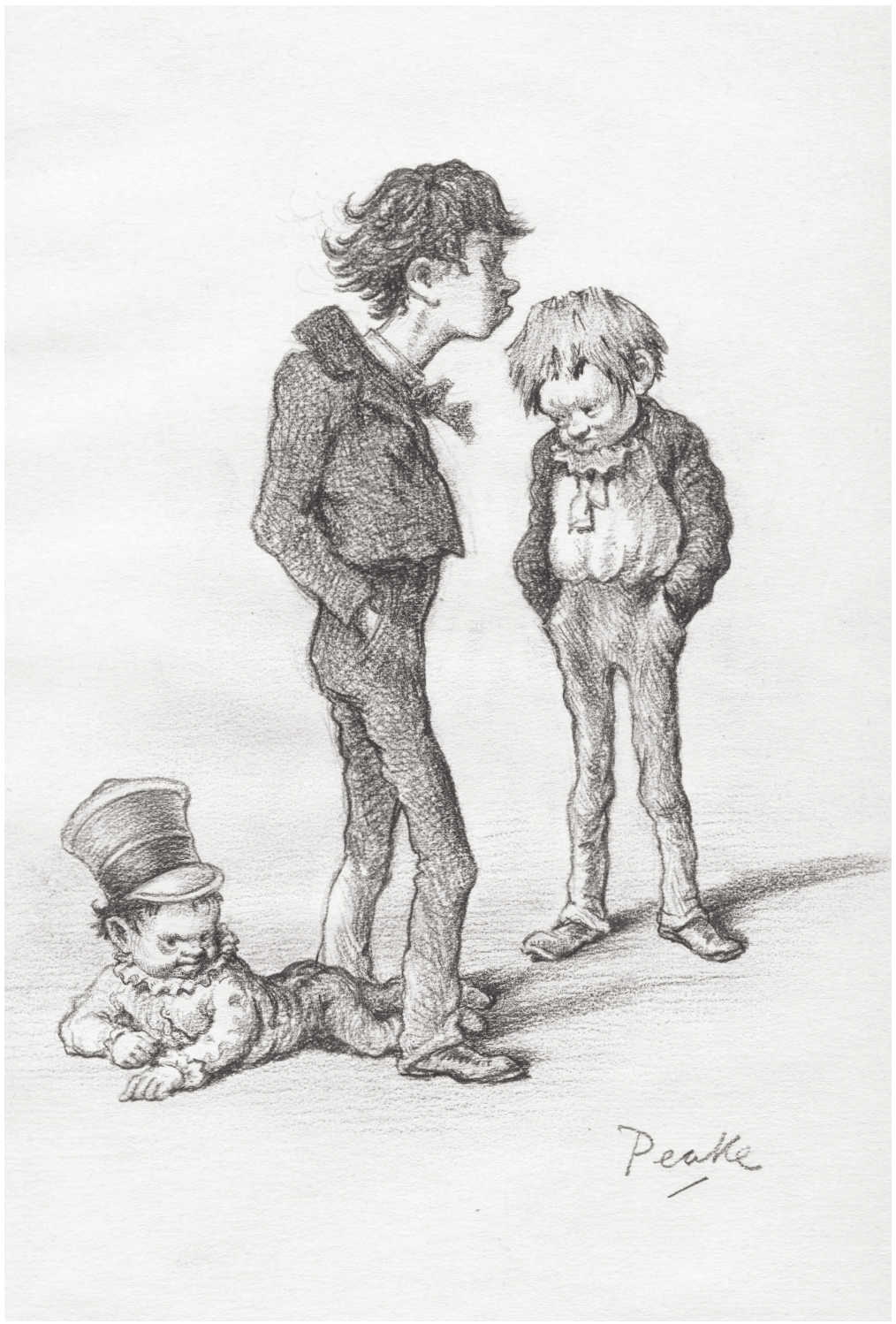




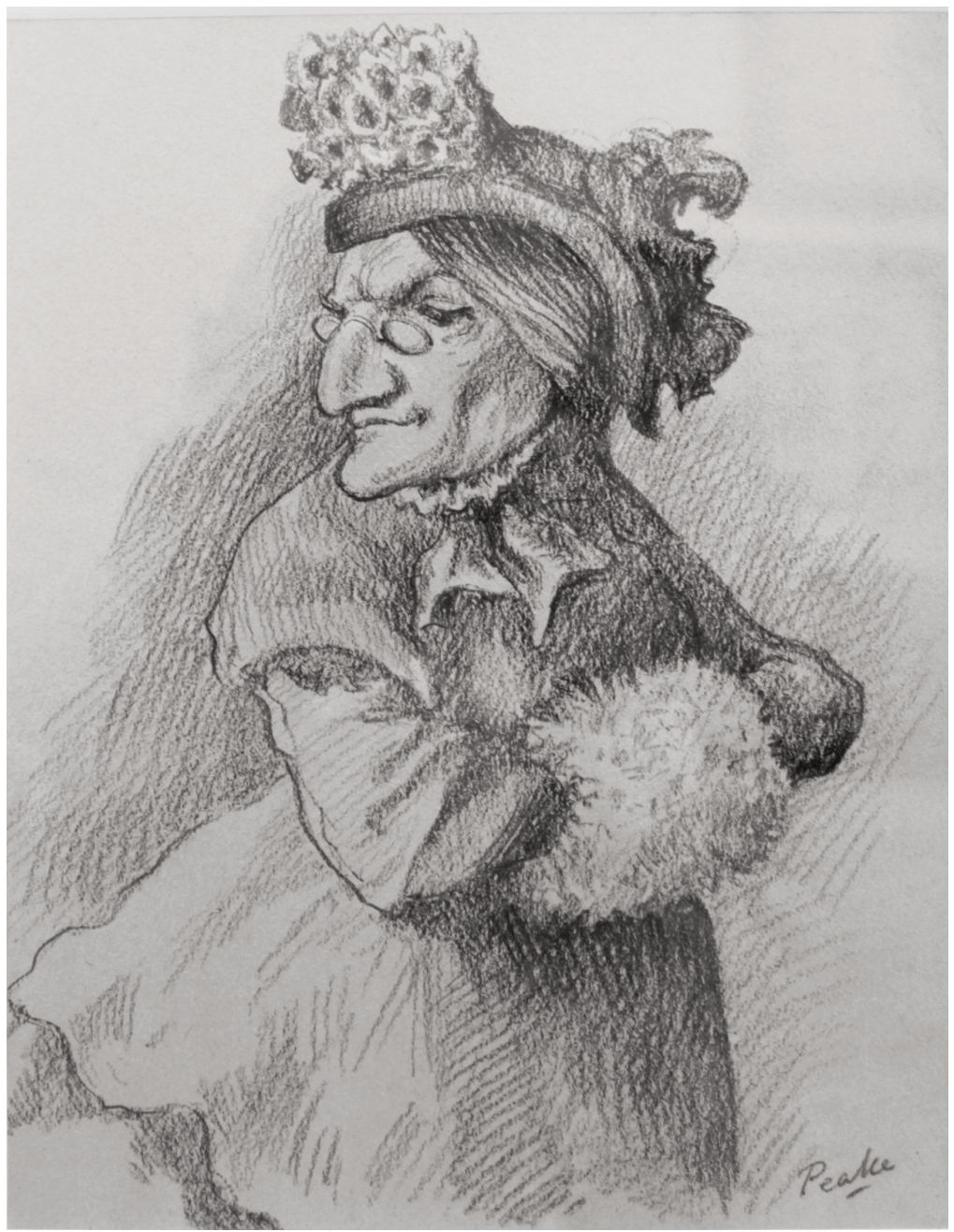

and above is Mrs Pardiggle herself.

Images very kindly supplied by Mike Kemp. Further details at http://www.kempbooksellers.co.uk/peake.htm 